\title{
High-Flux Solar Photon Processes
}

Donald C. Lorents, Subhash Narang, David C. Huestis, Jack L. Mooney, Theodore Mill, Her-king Song,

Susanna Ventura

SRI International

Menlo Park, California

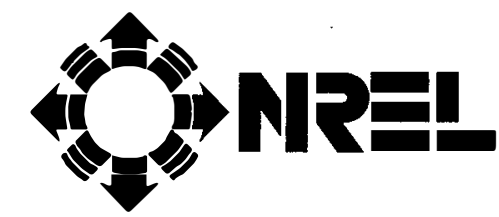

National Renewable Energy Laboratory A Division of Midwest Research Institute Operated for the U.S. Department of Energy Under Contract No. DE-AC02-83CH10093 


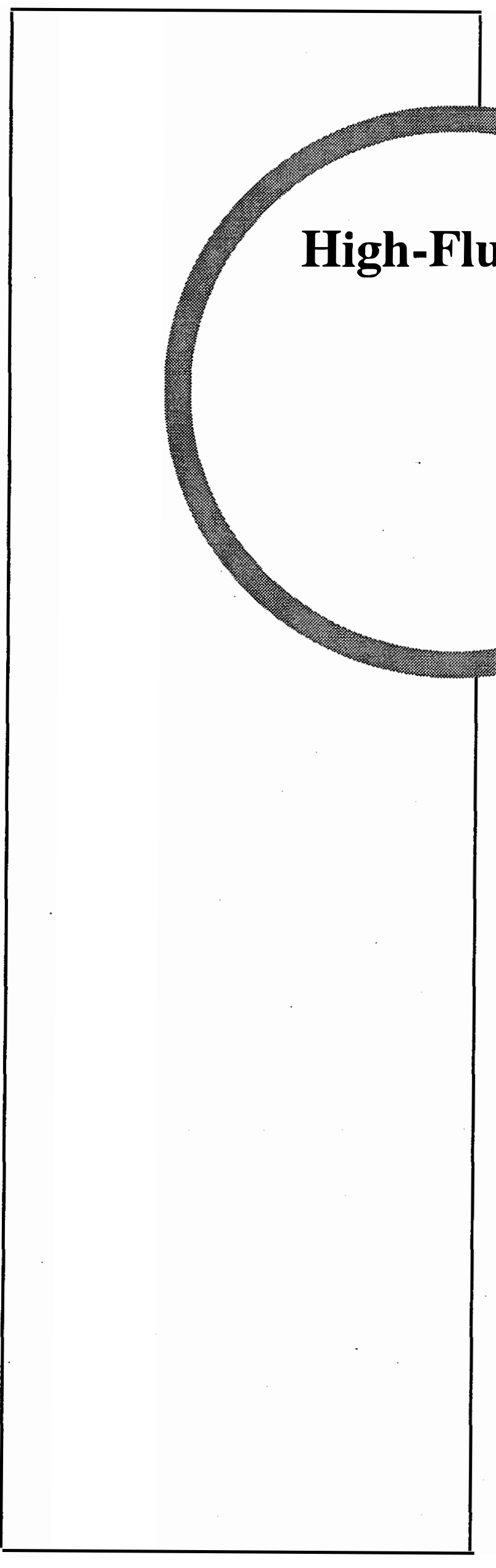

Donald C. Lorents, Subhash Narang,

David C. Huestis, Jack L. Mooney, Theodore Mill, Her-king Song,

Susanna Ventura

SRI International

Menlo Park, California

NREL Technical Monitor: Meir Carasso

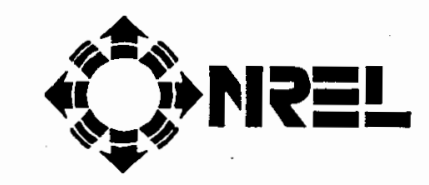

National Renewable Energy Laboratory

(formerly the Solar Energy Research Institute) 1617 Cole Boulevard

Golden, Colorado 80401-3393

- A Division of Midwest Research Institute Operated for the U.S. Department of Energy under Contract No. DE-AC02-83CH10093

Prepared under Subcontract No. XN-0-101131-1

June 1992 
On September 16, 1991 the Solar Energy Institute was designated a national laboratory, and its name was changed to the National Renewable Energy Laboratory.

\section{NOTICE}

This report was prepared as an account of work sponsored by an agency of the United States government. Neither the United States government nor any agency thereof, nor any of their employees, makes any warranty, express or implied, or assumes any legal liability or responsibility for the accuracy, completeness, or usefulness of any information, apparatus, product, or process disclosed, or represents that its use would not infringe privately owned rights. Reference herein to any specific commercial product, process, or service by trade name, trademark, manufacturer, or otherwise does not necessarily constitute or imply its endorsement, recommendation, or favoring by the United States government or any agency thereof. The views and opinions of authors expressed herein do not necessarily state or reflect those of the United States government or any agency thereof.

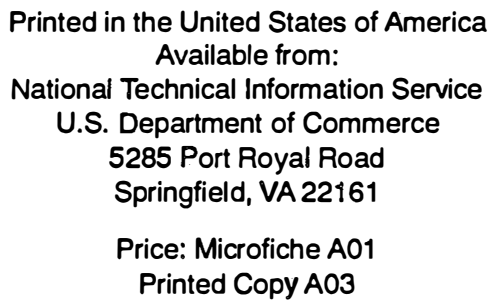

Codes are used for pricing all publications. The code is determined by the number of pages in the publication. Information pertaining to the pricing codes can be found in the current issue of the following publications which are generally available in most libraries: Energy Research Abstracts (ERA); Government Reports Announcements and Index (GRA and I); Scientific and Technical Abstract Reports (STAR); and publication NTIS-PR-360 available from NTIS at the above address. 


\section{SUMMARY OF FINDINGS AND RECOMMENDATIONS}

This study was commissioned by the National Renewable Energy Laboratory (NREL) for the purpose of identifying high-flux photoprocesses that would lead to beneficial national and commercial applications. The specific focus on high-flux photoprocesses is based on the recent development by NREL of solar concentrator technology capable of delivering record flux levels. We examined photolytic and photocatalytic chemical processes as well as photothermal processes in the search for processes where concentrated solar flux would offer a unique advantage.

\section{SOLAR-PUMPED LASERS}

\section{Findings}

Solar-pumped solid-state lasers with efficiencies in the $10 \%$ range have been demonstrated, and tunable dye lasers have been demonstrated using solar simulators. The NREL concentrator technology, properly mated with laser materials, offers a new opportunity for solar-pumped laser development that could greatly expand the capabilities of concentrated solar radiation. We believe that NREL's solar concentrator technology cannot effectively compete in commercial photochemical applications without the development of solar-pumped lasers that can generate high-quality tunable photon beams over a large range of frequencies. One photochemical process that has been demonstrated at the prototype production level is the enrichment of uranium isotopes by using sophisticated laser technology. Solar concentrator technology, used to pump high-power tunable lasers, appears to be capable of significantly reducing the costs of this process. Many important applications for solar-pumped lasers are associated with space-based missions, where solar energy is clearly the prime power source.

\section{Recommendations}

- We recommend establishment of a research effort on solar-pumped lasers that uses NREL's new solar concentrator technology to advance the development of efficient high-power, solid-state and dye lasers. A competitive program supported at several competent laboratories should be undertaken to investigate compatible laser materials, coupling solar flux to those materials, and scaling issues.

- We recommend establishing a collaboration with the National Aeronautics and Space Administration (NASA) on the development of solar-pumped lasers for space applications. 


\section{PHOTOCHEMICAL PROCESSES}

\section{Findings}

Commercial photochemical processes have been slow to develop, mainly because of the high cost of photons in comparison to thermal processes. Although the availability of lasers providing high-quality photon beams in a large range of energies has stimulated considerable research in photochemistry, particularly on the important problem of converting water to hydrogen and oxygen, successful economically competitive processes have yet to be demonstrated. We conclude that the application of concentrated solar radiation to photolytic or photocatalytic chemical processes is premature at this time; the successful application of concentrated solar radiation in this field will likely require the development of solar-pumped lasers.

\section{Recommendations}

- We recommend that NREL not undertake an engineering research effort directed toward the use of concentrated solar photons for these processes.

- In the area of photosynthesis and photodecomposition processes, insufficient basic information exists to support an applications-oriented effort at this time.

- We do recommend that NREL closely follow ongoing basic research efforts in this field and take advantage of any new discoveries that show a beneficial use of concentrated solar flux.

\section{MATERIALS PROCESSING}

\section{Findings}

We find that the materials processing area is the most promising area for applications of concentrated solar technology. This is a relatively new area in which the combination of photo and thermal radiation at the concentrated intensities available can be effectively used in many developing surface processing applications. The large area exposures possible with solar concentrators give this technology an advantage over other radiation sources for economical commercial applications. It is an area of well-recognized national and commercial needs that impact a wide range of technologies. Collaborative research efforts between government and industry should be possible and fruitful. 


\section{Recommendations}

- We recommend that NREL establish a strong, diversified research program at several qualified institutions to develop solar photothermal processes for surface modification of materials. Research in this field is ongoing at Hughes, SRI International, NREL, University of Colorado, University of Connecticut, and Stevens Institute of Technology.

- For specific applications the technical and economic advantages of solar, laser, and lamp processing technologies need to be carefully compared. Thus, it is essential to immediately canry out the necessary research while alternative technologies are still undeveloped. 


\section{CONTENTS}

SUMMARY OF FINDINGS AND RECOMMENDATIONS......................... i

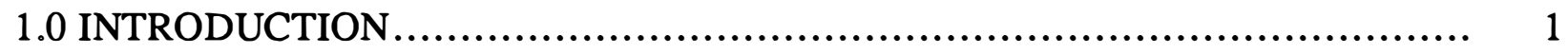

2.0 SOLAR-PUMPED LASERS ...................................................... 3

2.1 Applications of Solar-Pumped Lasers................................................... 5

2.2 Solar Concentrator and Laser Costs ................................................... 6

2.3 Recommendations ................................................................ 7

3.0 PHOTOCHEMICAL PROCESSES ............................................... 8

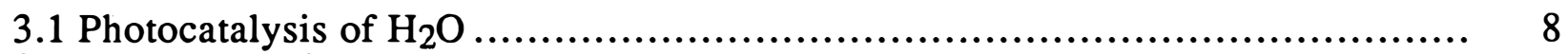

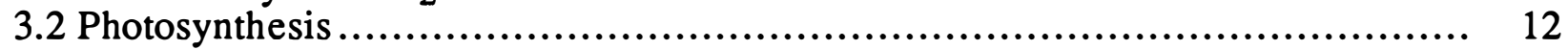

3.3 Photothermal Depolymerization of Polymers ....................................... 13

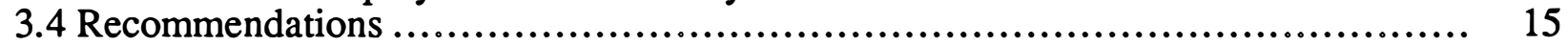

4.0 CONCENTRATED SOLAR RADIATION IN MATERIALS PROCESSING ...... 16

4.1 Materials Processing .......................................................... 16

4.1.1 Thin and Thick Films ............................................... 16

4.1.2 Ceramic Powders ........................................................ 19

4.1.3 Surface Modification...................................................... 21

4.2 Materials and Their Functional Role............................................... 23

4.2.1 Metal Oxides and Their Properties........................................ 25

4.2.2 Metal Nitrides and Carbides and Their Properties............................ 26

4.2.3 Metal Silicides and Their Properties........................................ 26

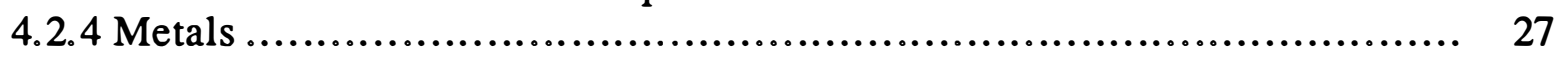

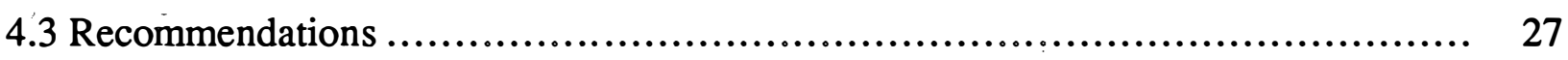

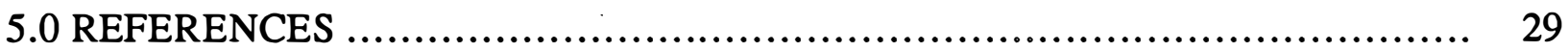




\subsection{INTRODUCTION}

The National Renewable Energy Laboratory (NREL) has developed a high-flux solar furnace capable of concentrations up to 50,000 suns by using an off-axis heliostat-concentrator combination in conjunction with a secondary nonfocusing compound parabolic concentrator. This facility has produced at the 20,000-sun level, a total power of $5 \mathrm{~kW}$ and a delivered flux of $2 \mathrm{~kW} / \mathrm{cm}^{2}$ [1]. Concentration near 50,000 suns is expected when the reflective secondary concentrator is replaced with a refractive concentrator. The refractive secondary concentrator design has achieved a record concentration of 84,000 suns on a small-scale system demonstrated at the University of Chicago [2]. While the flux produced by these concentrations is not comparable in intensity or optical beam quality to that of modern-day lasers, the ability to use high-intensity pulsed or continuous wave (cw) solar flux for large-area irradiations for thermal processing or photoprocessing might be expected to have practical, competitive applications.

With the expectation that such high solar flux facilities should lead to beneficial . applications, NREL commissioned this study for the purpose of identifying high-flux photoprocesses that can lead to practical applications. Such processes might include photolytic or photocatalytic chemical processes or photoprocesses combined with fast thermal processing that lead to the production of useful fuels, chemical products, or materials. The results of this study will be used to identify research directions leading toward applications of the high-flux solar resource, as well as researchers and organizations active in such research.

The study consisted of six tasks: (1) familiarization with the NREL high-flux solar resource, (2) a literature search for work on photo and photothermal processes, (3) initial screening, (4) setting of evaluation criteria and further evaluation of surviving processes, (5) assessment of the state of knowledge and research needs for promising processes, and (6) recommendations.

The study began with a comprehensive search of relevant literature on photochemical processes (excluding photodetoxification of hazardous wastes) from 1985 to 1990. This literature was searched for innovative photoprocesses that show promise of using high solar flux. The basic research in photochemical processes for the past decade has been greatly accelerated by the accessibility of lasers, resulting in the study of a multitude of homogeneous and catalytic reactions in the laboratory. Although many photochemical processes have been proposed for commercial application, few if any viable commercial chemical photoprocesses are in operation today. This observation alone did not bode well for the application of solar photons in the chemical process 
industries. The major conclusion of our study is that two areas appear most promising for future development: solar-pumped lasers, and materials processing utilizing both visible-ultraviolet photochemistry and thermal-infrared pyrolysis.

The solar-pumped laser literature was also reviewed, and although only a few groups are working in this area, the recent advance in concentrating solar flux should provide impetus for more rapid progress. Indeed, using a solar-pumped laser as an integral part of a solar concentrator system would give that system the desirable features of a high-power laser and allow a broader range of applications to be considered. Researchers working in photoprocesses strongly favor lasers as the photon source of choice because beams of photons from lasers can easily be manipulated in many ways, such as focusing, sweeping, pulsing, tuning, and frequency multiplication. The cost of photons is, however, a serious issue for most photochemical processes.

In the area of materials processing, rapidly developing technologies use photochemical and photophysical processes in an increasing variety of applications. Many technologies in the microelectronics field are beginning to use laser radiation for such processes as ablation, film deposition, etching, lithography, annealing, surface hardening, alloying, polymerization, and others. Many materials processes can effectively use the rapid thermal processing capability of the solar flux, and for certain applications the combination of photo and thermal processing can be advantageously used. The recent National Academy of Sciences/National Research Council (NAS/NRC) study [3] of national needs in the materials processing and synthesis areas offers substantial arguments for the development of new processing methods that would lead to new and better materials. Thus, the materials processing arena appears to be a promising one in which to seek applications for concentrated solar radiation. 


\subsection{SOLAR-PUMPED LASERS}

The record intensities of solar flux that have been demonstrated very recently with compound secondary elements (tens of kilowatts per square centimeter) still do not compare with those that are possible with coherent laser light, in which fluxes of megawatts (MW) to gigawatts (gW) per square centimeter are readily obtained; these intensities are easily reached because of the high optical quality of the beams projected by lasers, a property that permits them to be focused to pinpoint size with extremely high intensity. The high quality of beams from lasers also allows them to be projected for long distances with low loss, a feature that is extremely useful for many applications in which the radiation must be projected to a remote location. In contrast, nonfocusing concentrators deliver strongly diverging radiation that cannot be projected. In addition to their ability to focus, lasers operate on narrow-frequency bands, concentrating all their power within a narrow wavelength band. Many lasers can be tuned over a range of wavelengths and, when used with nonlinear frequency multiplication techniques, can produce a wide range of wavelengths extending continuously from ultraviolet (UV) to infrared (IR) wavelengths. These characteristics, together with the temporal pulse width control from subpicosecond to continuous wave (cw), modulation control, convenience of beam manipulation, and commercial availability, make the laser difficult to compete with as a source of radiation for most photo applications. Inefficiency and cost of operation are the major disadvantages of using lasers for commercial processing applications.

Most of the advantageous features of lasers can be realized for concentrated sunlight by the development of solar-pumped lasers. A solar-pumped laser, developed as an integral part of a solar concentrator, would provide orders-of-magnitude gains in such salient features as wavelength and intensity concentration, wavelength selectability, and remote delivery of power. The basic concept has been demonstrated on a small scale with solid-state lasers and is clearly feasible[4-6]. The power available from modest solar collectors permits the consideration of $\mathrm{cw}$ lasers capable of projecting large-area beams with total power in the 1- to 100-kW range. Such large-scale solar-pumped lasers could be quite efficient and be competitive with $\mathrm{CO}_{2}$ lasers that operate in the $10-\mathrm{kW}$ range at $10 \mu \mathrm{m}$. The future use of solar radiation for applications such as isotope separation or other photochemical or photomaterials processes needing high-intensity photons of specific energy will clearly require the development of solar-pumped laser technology before it can compete with even fairly inefficient electrically pumped lasers. As discussed in the following paragraphs, significant cost advantages may be realized if such lasers are developed. 
Solar pumping of lasers has been demonstrated, but research in this field developed slowly. Active research programs are currently under way at only a few laboratories. Currently, sustained active research programs on solar-pumped lasers can be found in the United States at NASA-Lewis [7] and in Israel [4] at the Weizmann Institute. Research on solar-pumped lasers has focused on solid-state and iodine lasers using small-scale concentrators. A major bottleneck in the development of solar-pumped lasers has been the lack of highly concentrated solar flux to exceed the threshold pump requirements of many laser media. The recent advances in the development of secondary nonfocusing concentrators demonstrating a significant increase in concentrated solar flux ( $>80,000$ suns) add several types of lasers, including tunable dye lasers, to the list of lasers that can be pumped. The removal of this major bottleneck should lead to the rapid development of efficient solar-pumped lasers as integral units of solar concentrators.

Solar pumping of solid-state lasers has been concentrated mainly at the Weizmann Institute in Rehovoth, Israel [4]. Researchers there have demonstrated 60-W cw laser power at $1.06 \mu$ from solar-pumped Nd:YAG rods at $2 \%$ efficiency. On the basis of this demonstration, and an analysis of the efficiency factors of solar pumping, they have projected total conversion efficiencies greater than $10 \%$ for solar pumping of solid-state lasers, such as alexandrite, that use a larger fraction of the solar spectrum. The Weizmann group recently demonstrated $100-\mathrm{W}$ peak power output from a Nd:Cr:GSGG (neodymium- and chromium-doped gadolinium scandium gallium garnet) solar-pumped laser operating near the $10 \%$ efficiency projected for this system [4a]. This laser material can be grown in large, high-quality crystals that would allow scaling of the solar-pumped lasers to high powers. New solid-state laser materials are continually being developed, and further improvements can be anticipated. Tunable solid-state laser materials such as Cr-doped GSGG or alexandrite and Ti:sapphire are examples of recent developments. The combination of these lasers with nonlinear frequency doubling and tripling permits extension of the wavelength range into the visible and near-UV range.

Solar pumping of gas-phase iodine lasers has progressed under NASA sponsorship to the point where large-scale systems can be designed [8] for high-energy operation in space applications of power beaming, propulsion, remote sensing, and long-range communication. Solar-pumped iodine lasers are very energy-inefficient because they use only the small UV portion of the solar spectrum $(<300 \mathrm{~nm})$ to photodissociate a perfluoroalkyl-iodide molecule that yields an inversion and lases at $1300 \mathrm{~nm}$.

In general, broadband tunable lasers have high pump power thresholds and require highpower flash lamps or other lasers to drive them; solar-pumped dye lasers have yet to be demonstrated. This is a significant goal because solar-pumped dye lasers operating in the visible wavelength range are potentially efficient as well as versatile. Rhodamine $6 \mathrm{G}$, for example, has its 
principal absorption band peak at $530 \mathrm{~nm}$, uses $15 \%$ of the solar irradiance, and has a quantum efficiency greater than $90 \%$. Pumping of a rhodamine $6 \mathrm{G}$ dye laser has been demonstrated using simulated solar radiation at concentration factors above 20,000 suns [8]. Thus, the successful solar pumping of dye lasers in a properly engineered system using the newly demonstrated concentration techniques will almost certainly be realized. Efforts are under way at the University of Chicago [6] to use the high-intensity solar radiation from a secondary nonimaging concentrator to demonstrate dye laser pumping. Frequency multiplication of tunable visible light yields tunable UV light, which is likely to have more interest for photochemical applications.

The promise of pumping lasers with solar radiation has been advanced considerably by the recent development of solar concentrators capable of delivering fluxes equivalent to $\sim 50,000$ suns. A solar-pumped laser can be an integrated element of a solar concentrator, providing a unit with all the capabilities of a laser for delivering photons. The possibility of delivering laser-quality photons with high power in the visible and UV range at low cost warrants further research; research should be devoted to the rapid development of solar-pumped lasers to determine their characteristics and establish a basis for their real costs. With the exception of the work at NASA, there is no serious, sustained effort in the United States toward the development of solar-pumped lasers.

\subsection{APPLICATIONS OF SOLAR-PUMPED LASERS}

The development of solar-pumped lasers is likely to lead to more applications for solar photons than for the concentrator technology alone, simply because of the control and flexibility of the photon beams that can be achieved by using laser sources. The development of low-cost laser sources that would allow economically competitive photochemical processing of fuels, specialty chemicals, or materials is an important key to commercial acceptance of photoprocessing methods.

The photochemical application of lasers was reviewed recently by Hackett [9] who gave an excellent summary of industrial photochemistry and promising uses of lasers for industrial photochemical synthesis reactions. In spite of the discovery of many elegant photochemical processes using lamps or lasers, very few if any are being applied commercially today. Although mercury lamps can operate with more than 50\% efficiency, they do not scale well for industrial processing because of their low flux. To be economically competitive, photochemical processing is limited to processes with high quantum yield or ones that produce high-value products. Hackett's review, however, does point to a number of isotope enhancement opportunities that could become commercially successful if production costs were reduced. Other possible applications of lasers in chemical and materials processing are discussed in other sections of this report. 
The only significant, proved photochemical application of lasers so far is in isotope separation. Laser isotope separation has been demonstrated for many elements, but most notable is the atomic vapor laser isotope system (AVLIS) technology in which the isotope enrichment of the 235 $\mathrm{U}$ in uranium fuel for reactors has been demonstrated on a pilot-plant scale at the Lawrence Livermore Laboratory (LLL) [10]. The next new uranium enrichment plant built in the United States will likely be based on the AVLIS technology. The lasers in the AVLIS system are dye lasers pumped with copper vapor lasers, a technology that is well proved and reliable but very expensive. The copper vapor lasers are about $1 \%$ efficient, but because of the good match to the dyes they pump, the dye laser efficiency is about $30 \%$. Thus, electrical-to-laser efficiency is about $0.3 \%$. The cost of photons from the AVLIS laser system, including operation and capital costs, is in the range of $\$ 20$ - $\$ 40 /$ einstein. This cost is prohibitive for the separation of isotopes other than uranium and thus limits the system's application for isotopes with lower economic value.

If solar pumping of tunable dye lasers proves feasible, the cost of isotope separation may be reduced by an order of magnitude by reducing the cost of photons to the $\$ 2-\$ 4 /$ einstein level. Some estimates give even lower costs, but realistic engineering cost estimates cannot be made at this time because of insufficient knowledge about solar-pumped lasers. At this level of cost, which still does not compete with the highly efficient mercury lamps that deliver photons at $\sim$ \$0.10/einstein, the isotopic enrichment of many more materials may become economical. Isotopes of interest include ${ }^{13} \mathrm{C},{ }^{30} \mathrm{Si},{ }^{91} \mathrm{Zr},{ }^{196} \mathrm{Hg},{ }^{157} \mathrm{Gd}$, and ${ }^{203} \mathrm{Tl}$ [9]. The issue of the cost of solar-pumped lasers is an important one that should be investigated further as soon as the engineering feasibility is established. The major cost issues are associated with the collection, concentration, and coupling of sunlight to the laser. Thus, the cost of the solar concentrator is expected to be the predominant cost.

Space applications of solar-pumped lasers are obviously the most suitable and important applications for these lasers, because solar energy for space-based missions is essential and available. For this reason, NREL should seek to collaborate with NASA on the research and development of solar-pumped lasers useful for space applications.

\subsection{SOLAR CONCENTRATOR AND LASER COSTS}

Although the solar photons are free, their collection and concentration require capital investment, equipment maintenance, and the operational costs of the high-flux-producing equipment. In an economic comparison of solar furnaces and arc lamps, Kolb [11] concludes that concentrated solar photons can be delivered for $\$ 7,000-\$ 13,000 / \mathrm{kW}$ in capital costs (compared with $\$ 50,000 / \mathrm{kW}$ for the NREL concentrator), which, if annualized with maintenance and 
operation costs, leads to total delivered energy costs of about $\$ 0.5-\$ 1.0 / \mathrm{kWh}$, or $\sim \$ .05 /$ einstein. If the energy is used for the sole purpose of laser pumping, that cost of delivered energy will probably increase by about a factor of 10-20 owing to inefficient use of the solar photons. An independent cost estimate presented by Winston [12] at the NRC Workshop on Applications of Concentrated Solar Photons also yielded an estimate of about $\$ 1 /$ einstein for 5\% efficient solarpumped laser photons in a large-scale uranium enrichment plant. Winston's independent cost estimate of copper-vapor laser-pumped dye laser photons is a factor of 10 higher at $\$ 10 /$ einstein but a factor of 2 lower than the costs reported for the AVLIS technology by LLL. Thus, within a factor of 2 there is agreement that solar-pumped laser technology applied to uranium isotope enrichment could yield a substantial cost savings on the order of a factor of 10. That fact alone justifies further research on the solar pumping of lasers, particularly tunable lasers operating in the visible range of wavelengths. Once such lasers are demonstrated, a more realistic cost analysis should be made to compare with the costs for AVLIS.

\subsection{RECOMMENDATIONS}

The prospects for developing and applying solar-pumped lasers appear very promising. Solar concentrator technology mated with new laser materials can lead to the development of efficient, high-power lasers that can deliver tunable photons from the UV to the IR. The economics of such lasers appear favorable for applications in the photoprocessing of materials. Therefore, we recommend:

- Establishing of a research effort on solar-pumped lasers that uses NREL's new solar concentrator technology to advance the development of efficient high-power solid-state and dye lasers. A competitive program supported at several competent laboratories should be undertaken to investigate compatible laser materials, coupling of solar flux to those materials, and scaling issues.

- Establishing a collaboration with NASA on the development of solar-pumped lasers for space applications. 


\subsection{PHOTOCHEMICAL PROCESSES}

One of the dreams of photochemists has been to use the radiant energy from the sun to directly and selectively produce chemicals of various sorts, ranging from fuels to selected isotopes. Although photochemistry is an old field, having begun with mercury lamps and developed strongly with lasers in the last two decades, the commercial applications of photochemistry are almost nonexistent today. From the commercial point of view, cost and scaling are the prime considerations and photochemical processes have largely been unable to compete on that basis. Only in the case of high-value chemicals is there an economic benefit, but the low volume of this market is not attractive to the chemical industry that is capable of investing in it. In this section, we discuss the photochemistry of fuels, photosynthesis of materials, and photodecomposition of polymers.

One of the highest hopes for the application of solar photochemistry is in the area of fuel production. Indeed, the nature of solar energy with its diumal and other variations dictates that some means of energy storage is required to buffer the fluctuations. A liquid or gaseous fuel would also simplify the transport of energy from solar-rich to solar-poor regions. The solar generation of liquid or gaseous fuel thereby becomes a prime requirement for the viability of any solar energy plant, whether it be photochemical, photovoltaic, or thermal. Another application often mentioned as a possible solution to an environmental problem is the solar photoreduction of $\mathrm{CO}_{2}$.

On the basis of this stimulus, the photochemical generation of fuel is a very active area of research worldwide [13,14]. Photocatalytic and photoelectrochemical means have received the most attention because of their ability, in principle, to use visible and near-UV solar radiation to generate fuels. Among the possible fuels, hydrogen generated from the photostimulated splitting of water is regarded as an ideal goal of solar energy generation because it is storable and transportable [15]. Thus, much of the ongoing research effort is devoted to the study of prototypical mechanisms for the photocatalytic and photoelectrochemical generation of hydrogen from water.

\subsection{PHOTOCATALYSIS OF $\mathrm{H}_{2} \mathrm{O}$}

The photocatalytic generation of $\mathrm{H}_{2}$ from $\mathrm{H}_{2} \mathrm{O}$ is generally accomplished in a solar photoelectrochemical cell of the type shown in Figure 1. These cells use semiconductor electrodes for light absorption and separation of the photogenerated electron-hole pair. Separation of the 


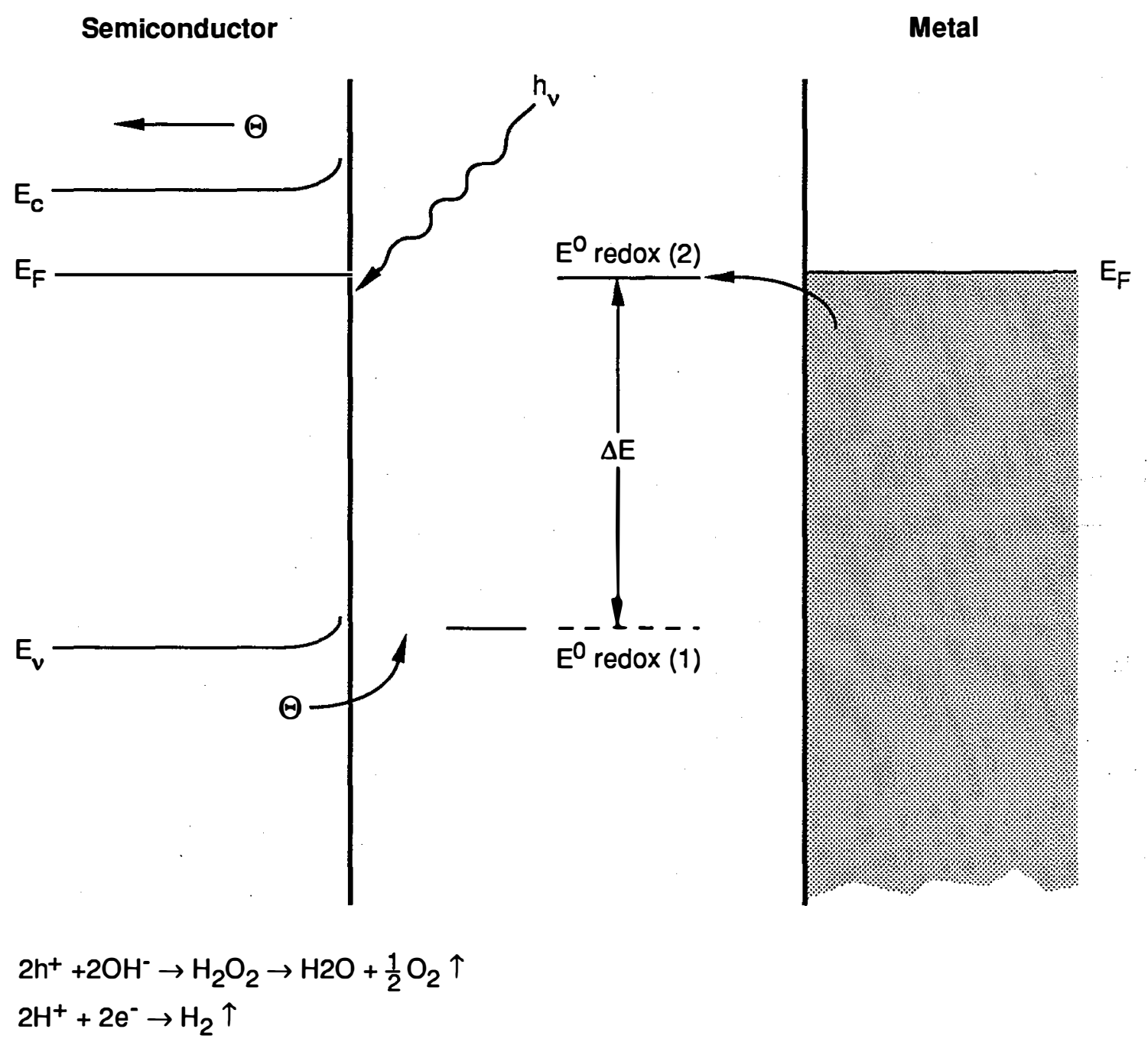

CM-1480-8

Figure 1. Band model for photoelectrochemical cell for optical-to-chemical energy conversion. 
charged pair at the semiconductor/electrolyte interface produces an electrical potential that drives the electrolysis, and this potential can be augmented with an external potential, if required, to supply the needed electrochemical potential. The adsorbed protons combine with electrons at the electrolyte/semiconductor interface, and the holes oxidize anions $\left(\mathrm{OH}^{-}\right)$at the opposite electrode. A catalyst such as $\mathrm{Pt}$ is required on the semiconductor electrode to promote the evolution of $\mathrm{H}_{2}$. Low-band-gap semiconductors are required for efficient use of the solar spectrum, but all such semiconductors are plagued with the problem of photocorrosion or photoinduced oxidation of the semiconductor. $\mathrm{TiO}_{2}$ is an excellent photocatalyst that is not hindered by photocorrosion but requires UV photons of wavelength $<400 \mathrm{~nm}$ (band gap $3 \mathrm{eV}$ ).

Recently, the concept of suspending semiconductor particles in the solution has been investigated as a means of providing a homogeneous solution for photon absorption. Increased efficiency is expected because of the reduced recombination of the charge carriers and shifting of the energy band gap owing to the influence of surface states. This area of active basic research appears to have promise but requires considerably more work to determine its feasibility. Because cost is the overriding factor that determines the acceptance of a fuel production process, the efficient use of solar radiation in a photochemical process becomes the important criterion in its adoption. Although under ideal conditions photochemical efficiencies can, in principle, reach $31 \%$ [16], the laboratory-demonstrated efficiencies so far have not exceeded $\sim 1 \%$ under real solar activation [16]. A Department of Energy (DOE) study [17] in 1984 on the quantum conversion processes of solar fuel production concluded that the practical efficiency of nonconcentrator photolysis of water would not be greater than $15 \%$. Bolton et al. [16] investigated the efficiency question in detail and agree with these conclusions. Practical realization of these efficiencies requires the use of a large fraction of the available solar spectrum, which in turn requires the use of low-band-gap semiconductors or multiple-band-gap systems.

We examined possible enhancement of photochemical processes with high-intensity concentrated solar radiation due to nonlinear effects or photothermal effects. The question of how the efficiency of photocatalytic or photoelectrochemical processes vary with photon flux is a central issue. Unfortunately, most research has focused on one-sun intensities, and little experimental work at higher than single-sun fluxes has been reported. The DOE report [17] suggested that a slight improvement in efficiency would be attained at modest concentration factors but at considerable added capital cost, resulting mainly from the more sophisticated system required for the concentrator (e.g., the tracking mirrors).

A major problem associated with the use of a high photon flux in electrochemical systems is that higher charge concentrations produced by the high flux lead to more rapid recombination losses, which can occur in the semiconductor as well as in the electrolyte. The recombination 
losses lead to the conclusion, on the basis of a simple model, that the photocatalytic reaction is proportional to photon intensity at low intensities but shifts to a square-root-of-intensity dependence at high intensities, at which the recombination becomes dominant. The photon intensity dependence has not been studied for $\mathrm{H}_{2} \mathrm{O}$-splitting reactions but has been experimentally confirmed in the case of photoredox reactions associated with catalytic oxidation of isopropanol and phenol on particulate $\mathrm{TiO}_{2}$ catalyst $[18,19]$. The results, which have been repeated for several other oxidation reactions [19], experimentally confirm the basic limitation of electron-hole recombination with increasing photon intensity. In these cases, the transition from linear to square-root dependence occurs near the intensity of one sun. Thus, the use of concentrated solar intensity leads to increasingly less efficient use of the radiation. Systematic experiments with the intensity dependence of the photoelectrochemical decomposition of water do not appear to have been performed.

Narrow-band-gap semiconductors are needed to improve the efficiency of using the solar spectrum for semiconductor catalysis of $\mathrm{H}_{2} \mathrm{O}$ splitting. Semiconductors such as $\mathrm{GaAs}$ with low band gap provide improved spectrum matching but suffer from the problem of photocorrosion (i.e., oxidation of the surface of the semiconductor induced by photoexcitation). Benitrand and Nozik have suggested [20] that this problem may be reduced at high flux under certain conditions (the first step of the redox reaction is reversible). Large-band-gap semiconductors such as $\mathrm{TiO}_{2}$ are less prone to suffer from photocorrosion, but their large band gaps $(>3 \mathrm{eV})$ can use only a small fraction of the solar spectrum. Concentration of the solar flux of photons $>3 \mathrm{eV}$ may be useful for a system using $\mathrm{TiO}_{2}$, provided that the rest of the flux is used separately for a different economic process. Another possibility is to develop a solar-pumped laser in the 600 - to $800-\mathrm{nm}$ range and frequency double its radiation to get photons in the 300- to 400-nm range. The solar pumping of lasers is discussed in Section 2.0 of this report. The use of particulate catalysts as colloidal suspensions has been tried in an attempt to increase the quantum efficiency of solar photocatalysis, but the effect of solar intensity on these systems has not been systematically investigated.

We conclude that research on photocatalytic processes is still very much in the basic research stage, where it must remain until the fundamental limitations of these processes are better understood. Not enough evidence exists at this time to conclude that concentrated solar flux offers enough benefit to the photocatalytic processes to justify an applications-oriented research program. The strong ongoing international research efforts in this field will undoubtedly lead to an understanding of the significant benefits and limitations of solar-powered photochemical fuel production in the next decade. That effort, which is supported largely by DOE in the United States 
and is active in Europe and Japan, should be followed continuously by NREL to take advantage of future breakthroughs.

\subsection{PHOTOSYNTHESIS}

Very few commercial synthetic reactions use photons to effect key reactions because of the high cost of photons compared with that of thermal processing. Exceptions occur because special circumstances provide favorable economics. The two major reaction types that fit this category are (1) long-chain radical processes and (2) stereoselective synthesis of natural products, usually specialty chemicals with high unit cost. Photochlorination or bromination of olefins or aromatics is an example of category (1), in which each mole (einstein)- of photons leads to several hundred moles of products. Photosynthesis of vitamin D exemplifies category (2). The process is characterized by a sequence of thermal and photosynthetic steps, the latter of which is a photoisomerization (stereoselective) of a cyclic triene by a wavelength-dependent scheme in which the competing process produces a toxic product. Judicious selection of wavelengths minimizes the side reaction, and the good stereospecificity of the photoprocess justifies use of the more expensive photons over a nonselective thermal reaction with expensive separation steps [20]. Photooxidative degradation of heparin to form low-molecular-weight heparin, a drug with longer-acting effects, is another example of photoprocessing a high-cost pharmaceutical product [22].

The economics that favor thermal processes over photoprocesses also favor broadband light sources over laser sources to promote photoreactions. Photons from medium-pressure mercury lamps (250-400 nm) cost approximately \$0.10/einstein; : in comparison, laser light near $308 \mathrm{~nm}$ costs $\$ 5.00 /$ einstein [23]. This large cost difference is not justified for most organic photosynthetic reactions, especially in the liquid phase, where absorption bands are broad and two-photon processes have little demonstrated synthetic use.

Donohue et al.[24] have described several examples of two-photon redox processes with solutions of ytterbium and samarium ions in which rates were nonlinear with laser power at $248 \mathrm{~nm}$. Whether these processes have enough added value to justify the use of laser sources remains to be seen. The principle of added value does apply to electronic-grade silane freed of trace arsine and phosphine impurities by their selective photo-oxidation with a UV laser in a spectral region where silane is transparent [25].

Solar radiation extends from $295 \mathrm{~nm}$ into the infrared. This spectral region has less utility for effecting organic photoprocesses, because most organic molecules do not absorb light above $300 \mathrm{~nm}$ [26]. Solar photons will affect only a subset of organic structures with extended chromophores, such as aromatic rings with nitrogen, oxygen, or sulfur attached or ketones and 
aldehydes. Among photosynthetic reactions of this subset, we have found no examples of processes with significant thermal barriers for which the high thermal (IR) fluxes in the solar collector will greatly accelerate the process. However, relatively few organic photolyses have been characterized in this way, so this conclusion is necessarily based on a slim collection of examples $[26,27]$.

In general, those photoprocesses forming radical pairs or triplet biradicals, which subsequently react thermally to form final products, are most likely to show significant enhancement in rates with increased temperature. The Norrish type II process with aromatic ketones is one example:

$$
\mathrm{PhC}(\mathrm{O}) \mathrm{CH}_{2} \mathrm{CH}_{2} \mathrm{CH}_{2} \mathrm{CH}_{3} \rightarrow \mathrm{PhC}(\mathrm{O}) \mathrm{CH}_{3}+\mathrm{CH}_{2}=\mathrm{CH} \mathrm{CH}_{3}
$$

Photoinitiation of vinyl polymerization or halogenation, in which long chains provide economical use of solar photons, also has modest thermal barriers and higher rates at higher temperatures:

$$
\begin{gathered}
\mathrm{XY} \rightarrow \mathrm{X} \bullet+\mathrm{Y} \bullet \\
\mathrm{X} \cdot(\mathrm{Y} \bullet)+\mathrm{n}>\mathrm{C}=\mathrm{C}<\rightarrow \mathrm{X}(>\mathrm{C}-\mathrm{C}<)_{\mathrm{n}} \mathrm{Y} \bullet \\
\mathrm{X} \bullet+>\mathrm{C}=\mathrm{C}<\rightarrow \mathrm{XC}-\mathrm{C} \bullet \\
\mathrm{XC}-\mathrm{C} \bullet+\mathrm{XY} \rightarrow \mathrm{XC}-\mathrm{CY}+\mathrm{X} \bullet
\end{gathered}
$$

The chief disadvantage in using higher temperatures to speed reactions (3) or (4) and (5) is the reversibility of (4) at higher temperatures, coupled with unwanted side reactions. These reactions are discussed in the following section.

\subsection{PHOTOTHERMAL DEPOLYMERIZATION OF POLYMERS}

Depolymerization of polymers is characterized by breaking the main-chain backbone to form smaller units of similar composition and monomer or other low-molecular-weight olefins and alkanes. The process typically requires temperatures above $150^{\circ}-200^{\circ} \mathrm{C}$. The simplest example is that of poly(methyl methacrylate) (PMMA), which decomposes above $200^{\circ} \mathrm{C}$ to form monomer quantitatively. Figure 1 in Grassie and Scott [28] illustrates how rapidly monomer is evolved from PMMA as a function of temperature. Table 1 lists several polymers and yields of their thermally formed monomers. 
TABLE 1. MONOMER YIELDS FROM POLYMERS ${ }^{a}$

\begin{tabular}{lll}
\multicolumn{1}{c}{ Polymer } & \% Monomer \\
\cline { 1 - 1 } Methyl methacrylate & & 100 \\
Methyl acrylate & trace \\
Styrene & 42 \\
a-Methylstyrene & 52 \\
Ethylene & $<1$ \\
Methacrylonitrile & 100 \\
Tetrafluoroethylene & 100 \\
\multicolumn{1}{c}{ a Source: Grassie and Scott ,1985. }
\end{tabular}

The data clearly show how structure affects depolymerization: Alkyl branching on the $\alpha$-carbon enhances monomer formation (unzipping) by repressing $\alpha-\mathrm{H}$ atom transfer to a carbon radical and oligomer formation (unbuttoning).

$$
\begin{gathered}
-(\mathrm{Ph})-\mathrm{CH}-\mathrm{CH}_{2}-\dot{\mathrm{C}} \mathrm{H}(\mathrm{Ph}) \rightarrow(\mathrm{Ph})-\dot{\mathrm{C}}-\mathrm{CH}_{2}-\mathrm{CH}_{2}(\mathrm{Ph}) \\
(\mathrm{Ph})-\dot{\mathrm{C}}-\mathrm{CH}_{2} \mathrm{CH}_{2}(\mathrm{Ph}) \rightarrow(\mathrm{Ph}) \mathrm{C}-\mathrm{CH}_{2}+\cdot \mathrm{CH}_{2} \mathrm{Ph}
\end{gathered}
$$

Thermal degradation of polymers is initiated by formation of a radical site on the main chain, usually by thermal cleavage at a weak link allylic to a terminal double bond. Photothermal degradation of polymers depends on photolytic creation of an initiating radical site, followed by conventional unzipping or unbuttoning. Because the major barrier to unzipping comes from thermal initiation, photothermal degradation greatly speeds the process, and unzipping can be observed at temperatures $100^{\circ}-200^{\circ} \mathrm{C}$ lower than for the thermal process alone. Mita and coworkers $[28,29]$ conducted a methodical study of photothermal degradation of polystyrene and PMMA using 365-nm light with an added ketone to photoinitiate the process.

The rate of unzipping of PMMA at $140^{\circ}-180^{\circ} \mathrm{C}$ depends on the amount of ketone added to the polymer film but is significantly accelerated by heating: at $180^{\circ} \mathrm{C}$, the weight loss is 15 times faster than at $140^{\circ} \mathrm{C}$, and over $70 \%$ of the monomer units are released in 20 minutes. In addition to increases in rate, increased temperature also increases the quantum yield $\left(\phi_{a}\right)$ for reaction of the photoinitiator and the average zip length. However, the values of $\phi_{a}$ decrease with increasing light 
intensity. This effect is thought to be caused by increasing competition between recombination (annihilation) of triplet ketones and $\mathrm{H}$-atom abstraction by the triplet ketones. Activation energies for the individual steps ranged from 8 to $14 \mathrm{kcal} / \mathrm{mol}$.

The effects observed with PMMA are similar to those found for polystyrene [31] with much faster rates of unzipping to low-molecular-weight oligomers by the photoprocess than by the thermal process.

The utility of photothermal degradation for recycling of important commercial polymers will depend on whether the advantages of combined photo and thermal reactions outweigh the added costs of solar collectors. The main advantage of lower temperatures for depolymerization is fewer side reactions during unzipping or unbuttoning. Moreover, there are scant data with which to judge possible nonlinear photon effects on any of these processes. Before any definitive decisions can be made about the utility of this process for the NREL high-intensity collector, a more detailed examination of depolymerization photokinetics and mechanisms needs to be performed with high-volume polymers with added value potential for recycled products, including monomers and oligomers.

\subsection{RECOMMENDATIONS}

In spite of considerable past and ongoing research on photocatalytic or photoelectrochemical fuel production processes, there is little evidence that concentrated solar flux is beneficial for these processes. We therefore recommend that NREL not undertake an engineering research effort directed toward the use of concentrated solar photons for these processes.

In the area of photosynthesis and photodecomposition processes, insufficient basic information exists to support an applications-oriented effort at this time.

We do recommend that NREL closely follow ongoing basic research efforts in this field and take advantage of any new discoveries that show a beneficial use of concentrated solar flux. 


\subsection{CONCENTRATED SOLAR RADIATION IN MATERIALS PROCESSING}

Material processing by concentrated solar radiation is a very promising area of development. Highly concentrated solar radiation has the ability to deliver high-energy-density fluxes of broadband radiation over large areas for both thermal processing and photoprocessing. The incident photon flux as well as the resulting thermal energy may promote several chemical or physical transformations either on surfaces or in bulk materials. Because of its simultaneous photolytic and pyrolytic effects, concentrated solar radiation may be competitive with other energy sources such as lasers or arc lamps.

Solar energy can be focused to produce solar fluxes with densities higher than $1 \mathrm{MW} / \mathrm{m}^{2}$. These solar fluxes may be delivered into solar furnaces, where very rapid thermal heating can be achieved over large surfaces, maintaining good control of flux and exposure time. Solar flux is also a versatile source for promoting photolytic processes in which single photons interact with the electronic structure of the materials, forming excitons or perturbing chemical bonds. Photolytic processes on surfaces are of particular interest. A 1-MW solar energy flux yields a total of $3.5 \times 10^{24}$ photons per second over the entire solar spectrum. This enormous number of photons can promote chemical and physical transformations over large surface areas at relatively shallow depths.

In view of these characteristics, high-energy solar fluxes may find interesting applications in materials processing and may favorably compete with other energy sources such as lasers or arc lamps. Solar induced rapid thermal processing may be used to allow surface modifications such as transformation hardening of tool steels, formation of high-temperature corrosion and wear-resistant coatings, and specialized processing of electronic materials, such as fabrication of thin film for multichips, ablation, microlithography, and surface modification. The processing of ceramic powders may also be assisted by solar-concentrated radiation, and three-dimensional objects can be fabricated.

\subsection{MATERIALS PROCESSING}

\subsubsection{Thin and Thick Films}

The microelectronic industry is increasingly using laser radiation for processes such as film deposition, etching, microlithography, ablation, surface modification, and others. High-energyflux solar energy has enormous potential in this area of development and may challenge the use of 
laser radiation. An important development of the microelectronic industry is the fabrication of thinfilm multilayer (TFML) interconnect structures on several substrates that can be incorporated into various package designs. Selective deposition of metals (from solution) on electronic substrates as high-density fine interconnections is highly desirable because it would allow a low-cost approach, avoiding any metal waste. On the other hand, the microelectronic industry is also looking at the fabrication of mixed metal oxide films, such as the high-temperature perovskite films, ferroelectric perovskite films, or electro-optic ceramics, as well as silicon nitrides or silicon oxide films for encapsulation.

The Polymer Chemistry and Technology Department of SRI International (SRI) has developed proprietary technology based on novel photoactive monomers and polymers suitable for the selective deposition of metallic, intermetallic, or ceramic films. We have successfully accomplished the selective deposition of metals, such as copper, gold, silver and nickel, as well as superconducting perovskite films, either by UV or laser-assisted chemical processing of monomer and polymer organometallic precursors from solution phase. These precursors have recently been developed by SRI. The scope of this technology would be greatly extended by the use of concentrated solar radiation processing that exploits a diversity of pyrolytic and photolytic reactions.

Our approach is based on spinning- (or dipping-) photolysis-pyrolysis processing of photopolymerizable organometallic precursors from solution. The technique is rather generic, and a variety of materials can be prepared by using different organometallic precursors.

Photopolymerizable organometallic precursors in solution are spin- or dip-coated on suitable substrates, polymerized on the entire substrate or partially through a mask by photoexposure to a UV lamp, and pyrolyzed. The use of concentrated solar energy could effectively increase the efficiency of this processing technique by performing photolysis and pyrolysis in a single step. Selective fabrication of high resolution patterns from polymer precursors would be achieved by exposing the precursor film to the high-density radiation through a mask. The high-energy-density solar flux would photoinitiate the polymerization of the monomer organometallic precursors after pyrolysis. The process would be very efficient because it eliminates one step, is selective, cures only the exposed area, and minimizes undesirable side reactions.

After this approach, we developed a low-cost solution process for the selective deposition of copper patterns on nonconducting substrates (such as printed circuit boards) with fine resolution and good adhesion and conductivity. A more recent development of our metal pattern fabrication technology is represented by the selective laser-assisted, solution-phase chemical deposition of thin metal films such as gold and nickel. The process is based on the laser-promoted decomposition of 
suitable organometallic polymer films. We have shown that metal films are formed directly after the organometallic polymer film is exposed to a laser for milliseconds. Metal patterns have been fabricated on insulating substrates, such as quartz, as well as on conducting substrates, such as nickel. Because metals with significantly different properties, such as gold and nickel, have been deposited by our laser-assisted technology, we believe this technology has strong potential for the fabrication of other metal patterns; it is highly suitable for interconnects of multichip modules. We have also fabricated films and patterns of perovskite superconducting films. Using them as interconnects in thin-film multilayer chips could significantly simplify the chip configuration by reducing the required number of layers.

Liquid-phase low-molecular-weight molecular precursors have been used by others to fabricate ceramic films by laser processing [32]. The rapid heating of the low-molecular-weight liquid precursor generates aerosol droplets through solvent boiling and evaporation. The largest aerosol droplets leave a solid on the substrate after solvent evaporation, while smaller droplets continue to react with the beam to form a range of deposits when they return to the surface. Particle-particle sintering is required to make a smooth film. In this process, the precursor's viscosity and evaporation rates are clearly critical factors affecting film preparation and morphology.

Solar-assisted deposition of surface coating materials may challenge, or in some cases assist, more traditional processing technologies such as chemical vapor deposition (CVD) for fabricating thin films. CVD finds many industrial applications in the fabrication of semiconductor devices, wear-resistant coatings, corrosion-protection coatings, and optical fibers. In a conventional CVD reaction, the substrates are placed in a fumace and reactive gases are passed over them. A high-temperature-induced chemical reaction takes place in the gas phase, and the resulting products are deposited on the substrate in the form of films. Although effective and reliable, CVD processing is slow, uses expensive and hazardous gas reactants, and may be applied only to materials capable of withstanding high temperatures.

Concentrated solar energy can, however, assist CVD processing by adding the important feature of rapid thermal heating and so overcome some of these limitations. Concentrated solar radiation applies itself to rapid thermal processing because it is capable of delivering high-energy fluxes at high uniformity over large surfaces. Rapid thermal processing (RTP) allows thermal budget (time-temperature) reduction by virtue of its short duration and by minimizing contamination of the deposited film by the substrate. Moreover, because RTP systems are capable of producing very fast temperature rises $\left(10^{5} \mathrm{C} / \mathrm{s}\right)$ for the NREL concentrator, rapid thermal heating and cooling may be used to control temperature-dependent CVD reactions. Two configurations of RTP-CVD processing have been adopted, the configuration depending on the 
source of rapid thermal heating. In one configuration the substrate is rapidly heated by two banks of air-cooled tungsten lamps, irradiating the substrate on each side (Figure 2a). This technology has been used for fabricating epitaxial silicon with high selectivity from dichlorosilane and hydrogen, without adding $\mathrm{HCl}[33]$ ] $\mathrm{TiSi}_{2}$ has also been selectively deposited without showing silicon substrate consumption or roughness at the silicide-silicon interface [34], an otherwise common drawback of conventional processing. In another configuration, rapid thermal heating is produced by a cw $\mathrm{CO}_{2}$ laser that passes parallel to and above the substrate through the precursor gases and induces a heterogeneous reaction on the substrate surface (Figure 2b). By this technique large-area silica films have been deposited on silicon substrates from a $\mathrm{SiH}_{4} / \mathrm{N}_{2} / \mathrm{Ar}$ gas mixture [35]. $\mathrm{A} \mathrm{CO}_{2}$ laser has also been used to deposit hydrogenated amorphous silicon films from $\mathrm{SiH}_{4}$ [36]. Similarly, silicon dioxide has also been deposited by excimer laser irradiation of mixtures of $\mathrm{N}_{2} \mathrm{O}$ as the oxidant and either $\mathrm{SiH}_{4}$ or $\mathrm{Si}_{2} \mathrm{H}_{6}$ as the $\mathrm{Si}$ source [37].

The favorable characteristics of rapid thermal processing that uses concentrated solar radiation can also be exploited in the thermal annealing of electronic film materials such as perovskite high-temperature superconducting films, ferroelectric films, or semiconductor films, for which the substrate contamination must be minimized to preserve the film performance.

\subsubsection{Ceramic Powders}

New techniques for processing advanced ceramic powders are sought to optimize the ceramic performance. Powders with fine particle size, narrow size range, and high purity are required, because macroscopic grains and impurities are responsible for structural defects. High-purity ultrafine ceramic powders have been produced from gas- and liquid-phase reactants in $\mathrm{CO}_{2}$ laser-induced processes. High-energy solar flux can prove to be an even better energy source than a $\mathrm{CO}_{2}$ laser because of its combined thermal irradiation and UV irradiation, which are capable of promoting pyrolysis and prepolymerization of ceramic precursors, respectively.

CVD processes initiated by laser-assisted photodecomposition of gas-phase precursors are under investigation in several laboratories. Photochemical reactors can be devoted to the production of high-purity ceramics by using a very favorable configuration in which pyrolysis takes place along the laser beam so that no contamination from hot surfaces is possible. Provided that the products are not stable gas-phase species and enough collisions occur during the interaction, solid particles can be grown; their composition and growth rate depend on the experimental conditions. 


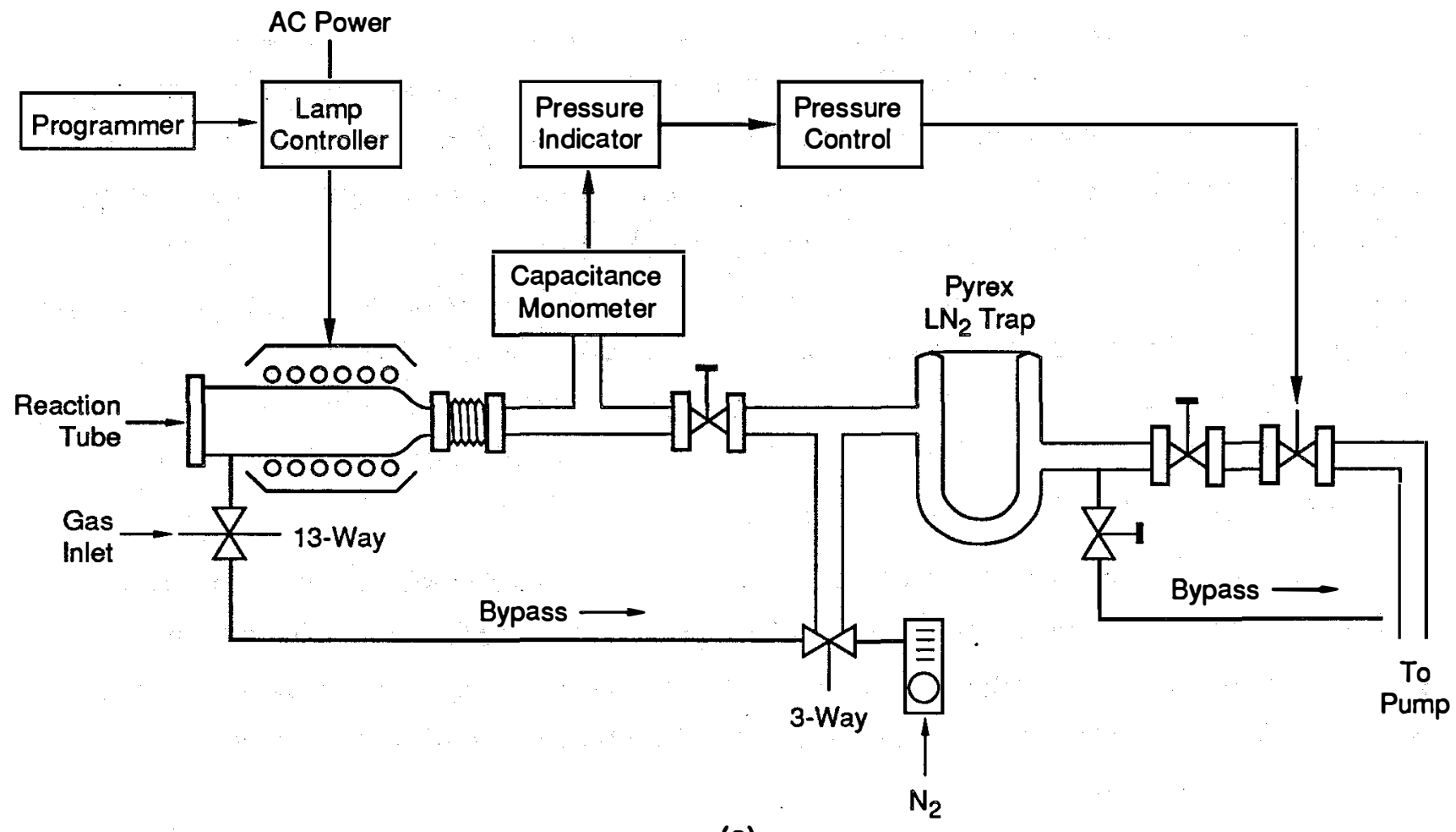

(a)

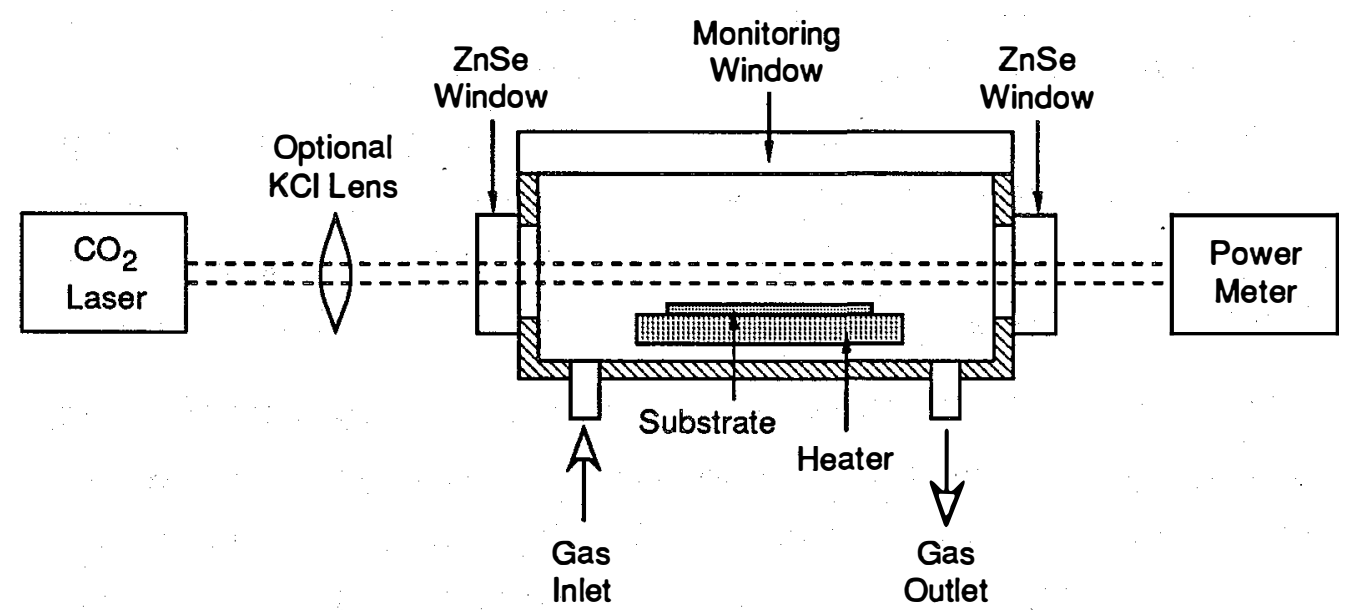

(b)

CM-1480-5A

Figure 2. Schematic representations of Rapid Thermal Processing-Chemical Vapor Deposition (RTP-CVD) setups. 
Ceramic powder processing by prepolymerization and pyrolysis of liquid organometallic precursors has also been developed by following a similar approach. Nanomaterials [materials wherein the constituent morphology is reduced to nanometer dimensions ( 5 to $100 \mathrm{~nm}$ )] have been prepared. An aerosol of organometallic liquid precursors is injected into the beam of a high-power carbon dioxide laser and converted to the corresponding ceramic. The unique combination of the precursor aerosol, generated by the ultrasonic nozzle, and rapid thermal processing allows the preparation of nanomaterials such as intermetallic, silicide, boride, nitride, carbide, and oxide phases. The radiant flux of concentrated solar energy meets the requirement of this high-power rapid thermal processing technique and can, in principle, be used instead of the $\mathrm{CO}_{2}$ laser.

Figure 3 shows the schematic of the laser-assisted fabrication technique. The fine aerosol droplets are rapidly polymerized into preceramic nanoparticles that can be either sintered in situ or collected for bulk processing. This technology is unique because of the possible formation of several nanocomposites, depending on the nature of the organometallic precursors used.

\subsubsection{Surface Modification}

Highly concentrated radiant energy can be delivered in large flux densities on solid surfaces to promote phase changes, atomic migrations, or chemical reactions. Material properties may be improved by these modifications: the surfaces can be made harder, or corrosion- or heat-resistant, or the coefficient of friction can be lowered.

Concentrated solar radiation has been used for hardening steel. The temperature is rapidly raised high enough to induce the formation of an austenitic phase, in which the carbon-containing phases are dissolved. Then the steel is rapidly cooled so that a transformation to the martensitic phase occurs. The extent of hardening is affected by heating and cooling conditions. The rapid thermal processing characteristics of concentrated solar energy, therefore, can be used effectively.

Surfaces can also be modified by cladding with corrosion- or wear-resistant materials made from powders. Laser cladding has been used in industry for surface treatment to improve wear resistance, corrosion resistance, and thermal protection since 1983. However, producing consistent products over long periods is understandably difficult because of the instability of the laser parameter, and powder-feeding parameters, when they are used, and the rise of the substrate temperature during processing. A more stable energy source from concentrated solar energy may effectively compete with laser technology for cladding with powders. 


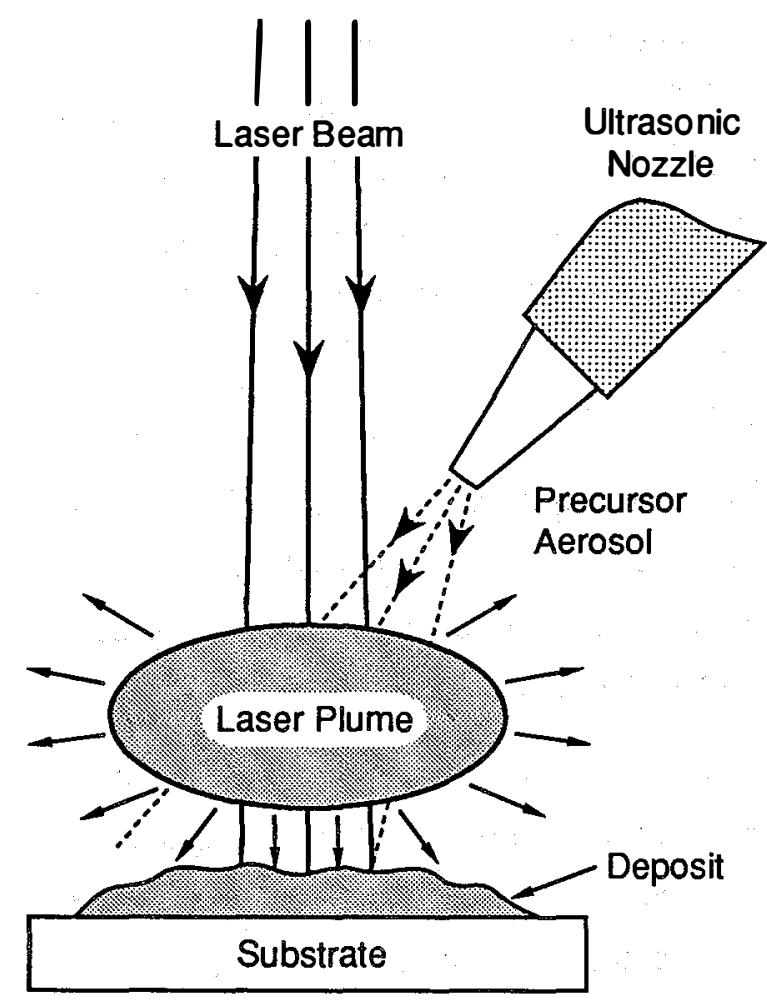

CM-1480-6

Figure 3. Laser-assisted ceramic processing. 


\subsection{MATERIALS AND THEIR FUNCTIONAL ROLE}

As previously discussed, ceramics and metals can be photothermally processed by means of concentrated solar energy, and, because of the simultaneous photolytic and pyrolytic effects, concentrated solar radiation may indeed be competitive compared with other energy sources such as lasers or arc lamps.

Materials such as ceramics, composites, or metal alloys are becoming increasingly important for various industrial applications. Ceramics based on certain specific oxides, nitrides, borides, and carbides are technologically important because of their mechanical, thermal, and chemical stability. Figure 4 illustrates the most representative high-performance ceramics, as well as their fields of application. The processing of these materials is crucial because it ultimately affects their performance. On the other hand, research on new metallic materials nowadays is focusing on innovative processing techniques to produce "materials by design." The alloy designer can engineer metals alone, in combination with ceramics, or in various different chemical states to optimize performance.

High-performance ceramics share mechanical strength, hardness, and wear resistance combined with high thermal stability and low density. Most of them are electrical and thermal insulators, but some combine a high electrical resistance with a high $\left(\mathrm{Al}_{2} \mathrm{O}_{3}, \mathrm{Si}_{3} \mathrm{~N}_{4}\right)$ and, in some cases, even a very high ( $\mathrm{AlN}, \mathrm{SiC}, \mathrm{BeO}$ ) thermal conductivity. Some are distinguished by semiconductor properties $(\mathrm{SiC})$ or ion conductivity $\left(\mathrm{ZrO}_{2}\right)$ and others show ferromagnetism (ferrite) or piezoelectricity $\left(\mathrm{PbZr}_{\mathrm{x}} \mathrm{Ti}_{1-\mathrm{x}} \mathrm{O}_{3}\right)$ and advantageous dielectrical properties $\left(\mathrm{BaTiO}_{3}\right)$ or are even optically translucent under certain conditions $\left(\mathrm{Al}_{2} \mathrm{O}_{3}\right)$.

How rapidly ceramics will achieve their potential will be determined largely by research on processing techniques, which first must overcome the problem of brittleness and then must prove to be economical. One processing requirement is either to eliminate defects-such as voids, agglomerations, and chemical impurities-from which cracks originate, or to toughen ceramics by devising ways to prevent cracks from spreading. Techniques also vary depending on the required material form: thin or thick films, powders, three-dimensional parts, or fibers. The previous section gives some indications about some forms of material processing.

Concentrated solar energy may find significant niches in this increasingly growing field of development. Rapid thermal processing assisted by high-energy solar flux has been extensively discussed. On the other hand, processing techniques for which photolytic and pyrolytic effects are required at the same time may be exclusive niches of development for high-flux solar energy. 


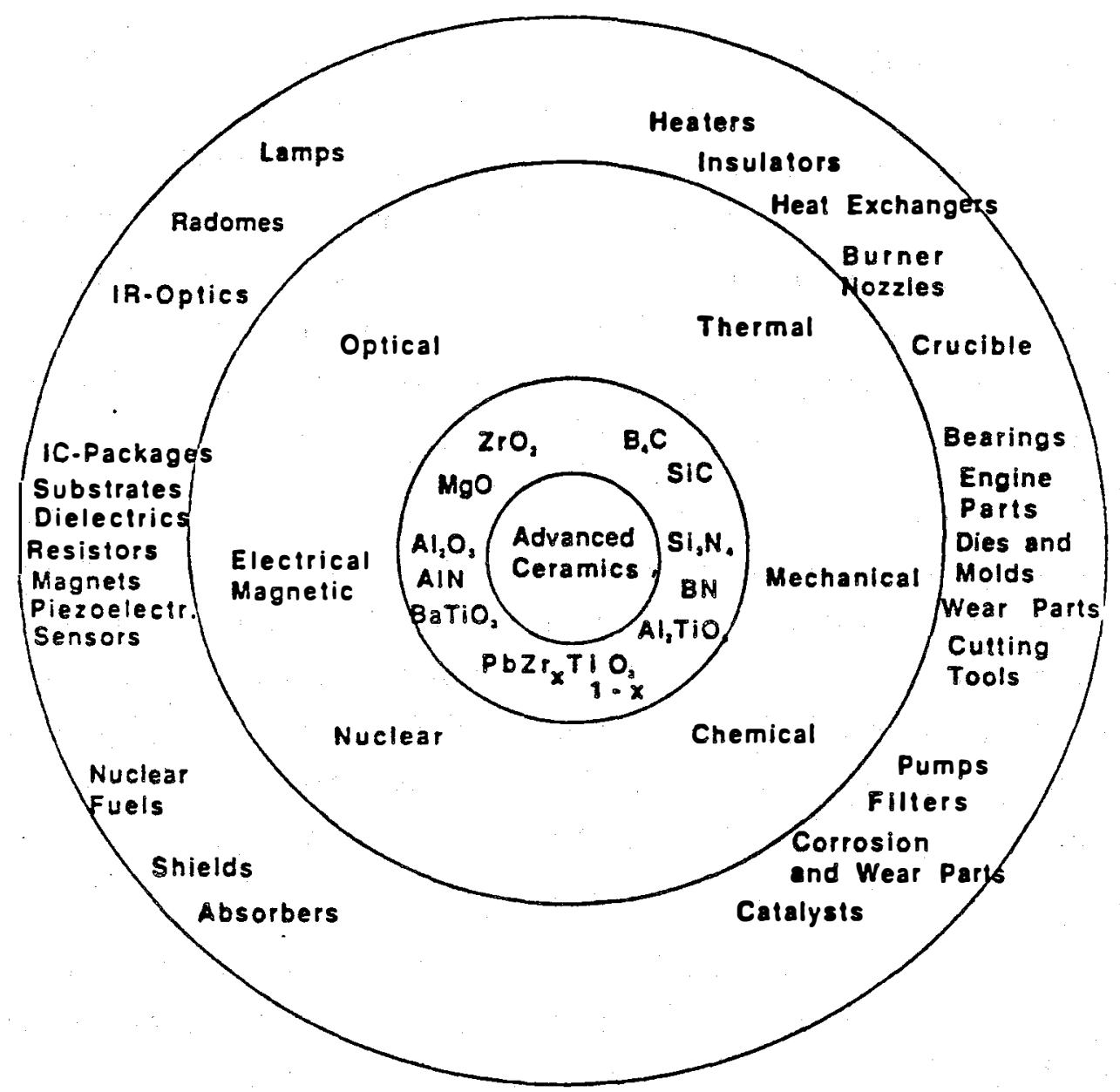

CA-1480-7

Figure 4. Metal oxides, their properties, and their applications. 
The following sections describe in detail the applications and uses of some highperformance ceramics are described in detail as follows.

\subsubsection{Metal Oxides and Their Properties}

Metal oxides are ubiquitous in a variety of technologies. Special properties such as ferroelectricity, optical nonlinearities, high optical transparency, and relative large, controllable refractive indices make metal oxides useful for a variety of applications. The progress made in the development of metal oxides has resulted in a strong contribution to the development of disciplines such as micro- and optoelectronics.

Metal oxides can be doped with transition metal ions that affect their optical properties allowing, for example, Ti doping of $\mathrm{LiNbO}_{3}$ to form waveguides and $\mathrm{Cr}$ doping of $\mathrm{Al}_{2} \mathrm{O}_{3}$ to form light emitters. Ion implantation has also been used for modifying surface properties of metal oxides. Electro-optic ceramics find an increasing number of applications as optical shutters, modulators, displays, color filters, image storage devices, and linear gate arrays for optical data processing. In many applications, electro-optic metal oxides are used as single crystals. The processing conditions used with these materials become important for finding reproducible and reliable conditions for fabricating crystalline films that have a high degree of perfection and are capable of replacing the single crystals. These films would be cheaper and would allow the use of a variety of substrates, so the films could eventually be integrated in to other technologies.

Piezoelectric ceramics, such as $\mathrm{PbZr}_{\mathbf{x}} \mathrm{Ti}_{1-\mathrm{x}} \mathrm{O}_{3}$ and $\mathrm{BaTiO}_{3}$, have been attracting increasing interest in the past ten years. They are preferred materials for use in a wide variety of electromechanical devices for applications such as high-intensity sonic and ultrasonic sources (sonar projectors, ultrasonic machining, welding, and humidifiers), lower-intensity sound sources (air transducers, delay lines, nondestructive evaluation instrumentation, and medical instrumentation), high-voltage pulse generators, sensors (hydrophones, microphones), nontransducer devices (electromechanical filters and voltage transformers), and positioning devices for fine control of motion.

Magnetic ceramics, most of ten represented by ferrite, are becoming increasingly important for electronic components. These materials may be specifically designed and tailored for several applications. Some of their most interesting applications are as permanent magnet materials, cores for high-frequency power supplies, recording heads for both audio and digital magnetic recording, memory cores in logic-digital computers, recording media, radar-absorbing materials, and many others. 
Recently discovered high-temperature superconducting (HTSC) ceramics have escalated interest in metal oxides. New HTSC materials can be tailored from a perfect dielectric to a superconductor simply by modifying the oxygen content. For their first applications, HTSC materials are now being developed in the form of films, for which high current densities have already been achieved. Processing conditions are again a major component in the performance of these materials. Bolometers, superconducting quantum interference devices (SQUIDs), interconnects for multichip modules, phase delay antennas, and high-Q devices are some of the applications now under development or recently developed.

\subsubsection{Metal Nitrides and Carbides and Their Properties}

Advanced ceramic materials such as $\mathrm{SiC}, \mathrm{Si}_{3} \mathrm{~N}_{4}, \mathrm{TiC}, \mathrm{TiN}, \mathrm{VC}, \mathrm{WC}$, and $\mathrm{BN}$ are chemically inert compounds with high thermal stability and mechanical strength. Such characteristics make these materials attractive candidates for applications such as heat engines, cutting tools, and turbine blades, which are now made with expensive superalloys. The chemical inertness of these materials makes fabrication a difficult task and places stringent demands on the purity of the starting materials. New synthetic approaches and new processing techniques are therefore required to fabricate these materials in the form of powders, coatings, or fibers of high quality. For this reason, the development of liquid preceramic precursors and their pyrolysis is now being extensively studied.

Silicon carbide is a good representative material of this class. Silicon carbide has exceptional physical and mechanical properties. It is one of the hardest materials known, second only to diamond and cubic boron nitride. $\mathrm{SiC}$ has low density, high inherent strength, and high thermal conductivity, stability at high temperatures and high resistance to thermal shocks. It is a commercial commodity, produced in amounts up to a million tons annually. $\mathrm{SiC}$ is also a semiconductor and is already being used or is a candidate material for use in high-temperature, high-frequency, and high-power electronic and optoelectronic devices.

The metal carbides and nitrides we have mentioned are also characterized by high thermal shock resistance, high-temperature strength, oxidation resistance, and high thermal conductivity.

\subsubsection{Metal Silicides and Their Properties}

Metal silicides have an essential role in modern silicon-based semiconductor fabrication technology, where they are used for various applications. They provide a diffusion barrier between the silicon substrate and a metal conductor layer, of ten gold or aluminum. This barrier

inhibits the interdiffusion of silicon and metal across the interface, which would otherwise occur rapidly at quite modest temperatures $(600-700 \mathrm{~K})$ and slowly even at room temperature. Metal 
silicides such as $\mathrm{PtSi}$ and $\mathrm{WSi}_{2}$ have been used for this application. Metal silicides are also used as rectifying contacts and switching devices to form Schottky barriers when deposited on suitably doped silicon substrates. They make interconnects and gates in very large scale integration (VLSI) devices. Silicides such as $\beta-\mathrm{FeSi}_{2}$ and $\mathrm{WSi}_{2}$ are semiconductors and can be used instead of or together with silicon to produce different gaps and electron mobilities in specialized devices.

Metal silicide films are also used as protective coatings on metals for avionics and space applications, on turbine blades, and on fuel cell electrodes. Also, electrodes for photoelectrochemical cells, when coated with silicides, show catalytic activity and could find use in solar energy conversion.

\subsubsection{Metals}

Very fine grained, single-phase materials can be achieved through advanced processing techniques, such as rapid solidification processing, permitting structural refinement and control of metastable and equilibrium phase conditions. Such materials can have excellent combinations of

strength, ductility, and corrosion resistance. Dispersion-strengthened and microduplex alloys can be prepared by mechanical alloying, creating unique microstructural configurations and leading, for example, to multiaxial properties or microstructures stable at high temperature. Intermetallic compounds can be made in polycrystalline, single-crystal, and amorphous forms by the use of novel processing techniques as well as compositional control and trace element additions. Metal matrix, intermetallic matrix, and ceramic matrix composites can be made by design and, again, are strongly dependent on processing conditions. Moreover, thin-film and layered structures can be fabricated and used in microelectronic applications, for example, as interconnects in multilayer chip modules.

\subsection{RECOMMENDATIONS}

The photothermal processing of high-temperature materials with high-intensity solar radiation appears to be a very promising area for applying the NREL solar concentrator technology. Photothermal processing is a rapidly developing field that now uses lasers and lamps, but concentrated solar radiation may have an economic advantage in some cases, such as large-area exposures. As discussed in the previous section, a wide variety of materials are included in this class and a correspondingly large number of processes need to be investigated. Research on the processing technology and economics of concentated solar radiation needs to be conducted to gain acceptance of solar concentrated technology by the commercial community. It is an area of intense national and commercial interest because new materials and surface coatings are basic to many current and developing technologies. 
We therefore recommend that NREL establish a strong diversified research program at several institutions to develop solar photothermal processes for surface modification of materials. Research in this field is ongoing at Hughes, SRI, NREL, University of Colorado, University of Connecticut, and Stevens Institute of Technology.

For individual applications, the technical and economic advantages of solar, laser, and lamp processing technologies need to be carefully compared. Thus, it is essential to immediately carry out the necessary research while alternative technologies are still undeveloped. 


\subsection{REFERENCES}

1. J. Rosen, "NAS Study," Mech Eng. 42 (Feb. 1991).

2. D. Cooke, P. Gleckman, H. Krebs, J. O'Gallagher, D. Sagie, and R. Winston, Nature 346, 802 (1990).

3. Committee on Materials Science and Engineering, National Research Council, Materials Science and Engineering for the 1990s (National Academic Press, Washington, D.C. 1989).

4. M. Weksler and J. Shwartz, IEEE J. Quantum Electron. 24, 1222 (1988).

4a. Y. Noter, M. Oron, J. Schwartz, M. Weksler, and A. Yogev, in, "Sixth Meeting in Israel on Optical Engineering," SPIE 1038, 512 (1988).

5. P. Gleckman, Appl. Optics 27, 4385 (1988).

6. R. Winston, University of Chicago (personal communication, 1990).

7. J. H. Lee, Presentation at the NRC/NAS Workshop on Potential Application of Concentrated Solar Photons (Nov. 1990).

8. J. H. Lee, K. C. Kim, and K. H. Kim, Appl. Phys. Lett. 53, 2021 (1988).

9. P. A. Hackett, "Making Light Work - Applications of Lasers to Chemical Production," Laser Chem. 9, 75 (1980).

10. Lawrence Livermore National Laboratory, "Overview of AVLIS Process and Alternative Applications," Report to the Energy Engineering Board NAS/NRC (Aug. 1990).

11. G. Kolb, "Solar Furnaces vs. Arc Lamps: A Comparison of the Economics of Energy Delivery," presented at the SERI Workshop on Potential Applications of Solar Photons (Nov. 1990).

12. R. Winston, An independent cost estimate, presented at the NRC Workshop on Applications of Concentrated Solar Photons (Nov. 1990).

13. A. Heller, in "Proceedings of the Robert Welch Foundation Conferences on Chemical Research," Vol. xxx, Advances in Electrochemistry Chap. V (publisher, city, 1986).

14. A. J. Bard, Ber Bunsenges. Phys. Chem. 92, 1187 (1988).

15. C. J. Winter, Int. J. Hydrogen Energy 12, 521 (1987).

16. J. R. Bolton, S. J. Strickler, and J. S. Connolly, Nature 310, 495 (1985).

17. D: B. Peterson, J. R. Biddle, and T. Fujita, Review of Solar Fuel-Producing Quantum Conversion Processes, DOE/JPL-1060-71 (DE85000336); JPL 84-32, Available from NTIS U.S. Dept. of Commerce (1984). 
18. T. A. Egerton and C. J. King, J. Oil Col. Chem. Assoc. 62, 386 (1979).

19. C. S. Turchi, "Effect of Light Intensity on Photocatalytic Reaction," presented at the SERI Workshop on Potential Applications of Concentrated Solar Photons (Nov. 7, 1990).

20. R. M. Benito and A. J. Nozik, J. Phys. Chem. 89, 3429 (1985).

21. H.J.C. Jacobs and E. Havinga, in "Advances in Photochemistry, Vol. II," G. S. Hammond and K. Jollnick, Eds. (Wiley \& Sons, New York, 1979) p. 305.

22. K. H. Pfortner, J. Photochem. Photob(O) A:, Chem. 51, 81 (1990).

23. P. A. Hackett, Laser Chem. 9, 75 (1988).

24. T. Donohue, in "Applied Laser Photochemistry, the Liquid Phase," in Laser Applications in Physical Chemistry," D. K. Evans, Ed. (M. Dekker, New York, 1990).

25. J. H. Clark and R. G. Anderson, Applied Phys. Lett. 32, 46 (1978).

26. J. C. Calvert and J. Pitts, Photochemistry (John Wiley \& Sons, New York, 1968).

27. P. de Mayo, Excited States in Photochemistry (Academic Press, New York, 1978).

28. N. Grassie and G. Scott, Polymer Degradation and Stabilization (Cambridge University Press, 1985).

29. K. Horie, K. Morishita, and I. Mita, Macromol. 17, 1746 (1984).

30. I. Mita, T. Hisano, K. Hora, and A. Okamoto, Macromol. 21, 2003 (1988).

31. I. Mita, K. Obata, and K. Obie, Polym. J. 22, 397 (1990).

32. A. P. Magee, P. R. Strutt, and K. E. Gonsalves, Chem. Mater. 2, 232 (1990).

33. J. L. Regolini, D. Bensahel, J. Mercier, and E. Scheid, J. Cryst. Growth 96, 505 (1989).

34. J. L. Regolini, D. Bensahel, G. Bomchil, and J. Mercier, Appl. Surf. Sci. 38, 408 (1989).

35. T. Szorenyi, P. Gonzales, D. Fernandex, J. Pou, B. Leon, and M. Perez-Amor, SPIE Proc. Vol. 1279, 144 (1990).

36. R. Bilenchi, I. Gianinoni, and M. Musci, Mater. Res. Soc. Symp. Proc. 17, 199 (1983); M. Meunier, J. H. Flint, J. S. Haggerty, and D. Adler, J. Appl. Phys. 62, 2812 (1987); D. Metzger, K. Hesch, and P. Hess, Appl. Phys. A 65, 345 (1988); P. Gonzalez, M. D. Fernandez, B. Leon, and M. Perez-Amor, Proceedings of the Ninth E. C. Photovoltaic Solar Energy Conference, W. Paltz, G. T. Wrison, and P. Helm, Eds. (enter publishers, 1989), pp. 1017.

37. A. Tate, K. Jinguji, T. Yamada, and N. Takoto, Appl. Phys. A 38, 221 (1985). 


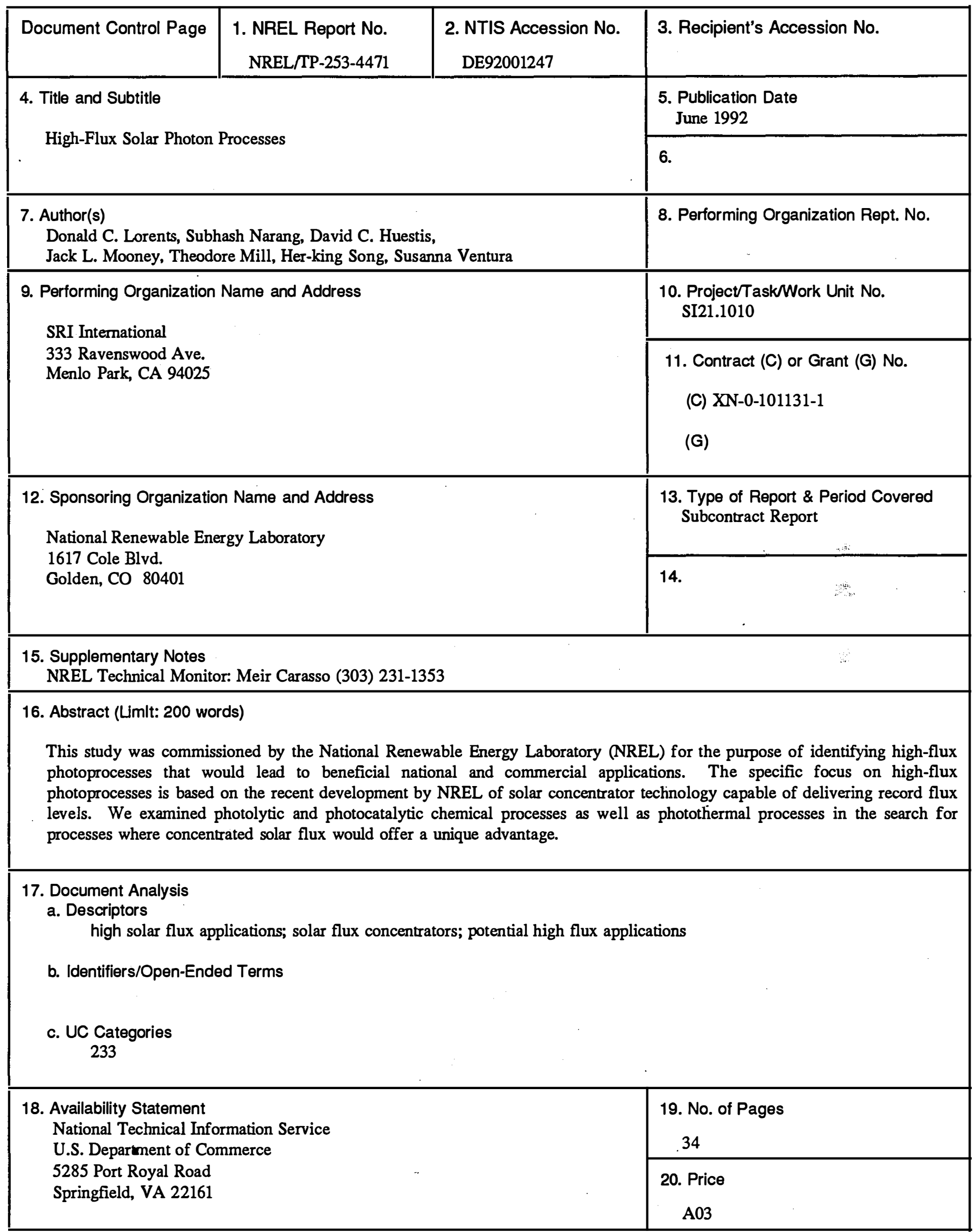

Form No. 0069E (6-30-87) 